\title{
Preservation of complete anal sphincteric proprioception in restorative proctocolectomy: the inhibitory reflex and fine control of continence need not be impaired
}

\author{
W G Lewis, M E R Williamson, A S Miller, P M Sagar, P J Holdsworth, D Johnston
}

\begin{abstract}
This study evaluates whether reflex function of the anal sphincter remains unchanged after restorative proctocolectomy, provided that the sphincter remaining is kept intact, without mucosal stripping or endo-anal anastomosis. Paired tests of anorectal function were performed before, and a median of 6 (range 2-12) months after restorative proctocolectomy with stapled, end to end pouch-anal anastomosis. Beforehand, distension of the rectum with $50 \mathrm{ml}$ of air produced a median (interquartile range) increase in pressure within the rectum of 22 (15-29) $\mathrm{cm} \mathrm{H}_{2} \mathrm{O}$ and reflex inhibition of the anal sphincter from a pressure of 76 (62-106) $\mathrm{cm} \mathrm{H}_{2} \mathrm{O}$ to a pressure of 34 $(15-52) \mathrm{cm} \mathrm{H}_{2} \mathrm{O}$. After the procedure, distension of the ileal pouch with $50 \mathrm{ml}$ of air produced an increase in pressure within the pouch of only $5(4-8) \mathrm{cm} \mathrm{H}_{2} \mathrm{O}(\mathrm{p}<0.001$ compared with beforehand) and reflex inhibition of the anal sphincter from a pressure of $62(25-79) \mathrm{cm} \mathrm{H}_{2} \mathrm{O}$ to 37 (17-68) $\mathrm{cm} \mathrm{H}_{2}$ O. Maximal reflex inhibition of the upper third of the anal sphincter to a pressure of $26(15-48) \mathrm{cm} \mathrm{H}_{2} \mathrm{O}$ was observed when pressure within the pouch increased by $16(11-22) \mathrm{cm} \mathrm{H}_{2} \mathrm{O}$. After restorative proctocolectomy, all patients were continent (two experienced minor nocturnal leakage of mucus) and 25 could discriminate between flatus and faeces. Thus, reflux function was preserved in response to changes in pressure, ensuring that the subtler aspects of anal continence were preserved.

(Gut 1995; 36: 902-906)
\end{abstract}

Keywords: ulcerative colitis, anorectal physiology

Academic Unit of

Surgery and Centre for

Digestive Diseases,

The General

Infirmary, Leeds

W G Lewis

M E R Williamson

A S Miller

P M Sagar

P J Holdsworth

D Johnston

Correspondence to: Mr W G Lewis, Academic

Unit of Surgery,

Unit of Surgery,

The General Infirmary

Great George Street,
Leeds LS1 3EX.

Leeds LS1 3EX.

23 September 1994 ileal pouch-anal anastomosis remains controversial, however, since the reflex is thought to be mediated by an intramural nerve plexus, ${ }^{2}$ which must, of necessity, be transected in the course of the procedure. Nevertheless, we have shown previously that the reflex does return after operation and that this coincides with the return of the patient's ability to discriminate between flatus and faeces and to pass flatus with confidence without fear of faecal leakage. ${ }^{3}$

The existence of the recto-anal inhibitory reflex is usually expressed qualitatively: present or absent, plus or minus, with no attempt at quantitation. In this study we have endeavoured to quantify the reflex activity of the anal sphincter both before and several months after restorative proctocolectomy. Our hypothesis was that provided the functional anal sphincter was preserved intact at operation, without mucosal stripping or endo-anal anastomosis, the reflex properties of the sphincter would also be preserved.

\section{Patients and methods}

A consecutive series of 30 patients ( 10 men, 20 women) was studied. Each patient underwent restorative proctocolectomy for what was thought to be ulcerative colitis, though two patients subsequently proved to have Crohn's disease on pathological examination of the resected specimen. The median age was 33 (range 14-62) years. Each patient underwent end to end ileal pouch-anal anastomosis, 1-2 $\mathrm{cm}$ above the dentate line, without stripping of the anal mucosa. ${ }^{4}$ A duplicated $(D)$ reservoir was constructed in 17 patients and a quadruplicated $(\mathrm{W})$ reservoir in 13 patients, 30 to $40 \mathrm{~cm}$ of distal ileum being utilised for that purpose in each case. Ten patients had a one stage operation without defunctioning ileostomy and 20 patients had a two stage procedure with a temporary defunctioning ileostomy.

\section{LABORATORY STUDIES}

Each patient underwent tests of anal sphincter function before operation and a median of 6 (range 2-12) months after operation or closure of the ileostomy. The resting anal sphincter pressure was measured at $1 \mathrm{~cm}$ intervals along the anal canal by means of a $5 \mathrm{~mm}$ diameter water filled balloon. The pressure at each station was measured for at least one minute, or until the recording became stable. Pressure in the system was transmitted via a transducer and amplifier ( 3552 Ormed Ltd, Welwyn Garden City, UK) to a chart recorder (5041 Ormed Ltd). ${ }^{4}$ Threshold electrosensitivity of the mucosa of the anal canal was measured in the upper, mid, and lower anal canal 
(determined by anal manometry) by means of a bipolar constant current stimulator probe lubricated with a solution of KY Jelly (Johnson and Johnson, Slough, UK) and normal saline in equal quantities. ${ }^{5}$ The rectal inhibitory reflex was assessed by measuring the response of the entire length of the anal sphincter to distension of a balloon placed within the rectum or ileal reservoir at a rate of $1 \mathrm{ml} / \mathrm{s}$. Any decrease in anal pressure was taken to denote a positive reflex. ${ }^{6}$

\section{CLINICAL ASSESSMENT OF OUTCOME}

The quality of anal continence was assessed by direct questioning of the patients about faecal leakage, anal soreness, the ability to defer defecation, and the ability not only to discriminate between flatus and faeces but actually to release flatus safely while standing or sitting without fear of even minor faecal leakage.

\section{STATISTICAL ANALYSIS}

All grouped data were expressed as median and interquartile range (IQR). Groups were compared by means of the Wilcoxon matched pairs signed rank test for paired data. ${ }^{7}$

\section{Results}

ANAL PRESSURE

The pressure profiles of the resting anal sphincter before and after operation is shown in Figure 1. Peak anal pressure was lower after operation, and the decrease in pressure after restorative proctocolectomy was statistically significant at 1.5 and $0.5 \mathrm{~cm}$ from the anal verge $\left({ }^{\star} p=0.036\right.$ and ${ }^{\star \star} p=0.008$ respectively). The length of the anal sphincteric high pressure zone did not change significantly; it was $3.5(2-4.5) \mathrm{cm}$ before and $3.5(2-4.5) \mathrm{cm}$ after operation.

\section{Before surgery}

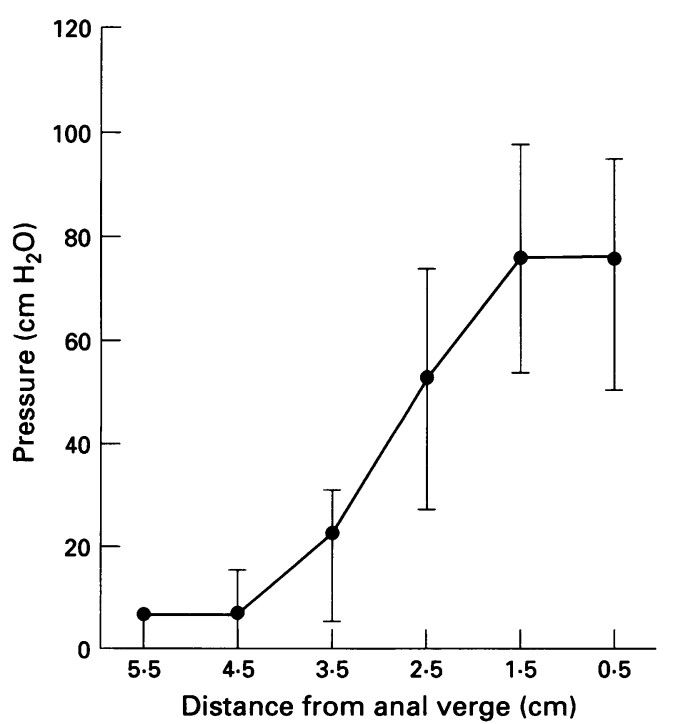

\section{ANAL SENSATION}

Sensory thresholds before operation in the upper, mid, and lower anal canal were $9 \cdot 1$ $(6 \cdot 6-12 \cdot 1), 7 \cdot 4(5 \cdot 7-8 \cdot 3)$, and $6 \cdot 6(4 \cdot 3-9 \cdot 5)$ $\mathrm{mA}$ respectively. After restorative proctocolectomy there was no significant change, the corresponding thresholds were $10.3(7 \cdot 7-14.5)$, $8 \cdot 3(6 \cdot 6-11 \cdot 1)$, and $7 \cdot 3(4 \cdot 8-9 \cdot 0) \mathrm{mA}$.

\section{RECTO-ANAL INHIBITORY REFLEX}

The recto-anal inhibitory reflex was present in all patients before operation. The change in the pressure profile of the anal sphincter during distension of the rectum is shown in Figure 2. The pressures measured during distension of the rectum were significantly lower than resting anal pressures at each station $(p<0.001$ at $3.5,2.5$, and $1.5 \mathrm{~cm}$ from the anal verge and $\mathrm{p}=0.002$ at $0.5 \mathrm{~cm}$ from the anal verge).

\section{POUCH-ANAL INHIBITORY REFLEX}

A pouch-anal inhibitory reflex was also found to be present in each patient a median of 6 (range 2-12) months after operation or closure of the ileostomy. The pressure measured in the anal sphincter during distension of the pouch with $50 \mathrm{ml}$ of air were significantly lower than resting pressures at $2.5 \mathrm{~cm}$ and $1.5 \mathrm{~cm}$ from the anal verge $(p<0.02$ at each station - Fig 3). At maximum inhibition of the sphincter, the pressures measured at $3.5 \mathrm{~cm}, 2.5 \mathrm{~cm}, 1.5 \mathrm{~cm}$, and $0.5 \mathrm{~cm}$ from the anal verge were all significantly lower than resting anal pressure $(p=0.003, p<0.001$, $\mathrm{p}<0.001$, and $\mathrm{p}=0.003$ respectively) and also lower than that observed with distension of the pouch with $50 \mathrm{ml}$ of air $(\mathrm{p}<0.005, \mathrm{p}<0.001$, $\mathrm{p}=0.002$, and $\mathrm{p}=0.003$ respectively). This change in the pressure profile of the anal sphincter during distension of the pouch is shown in Figure 4. It is of note that the pressure profile during distension of the ileal pouch did not differ significantly from that

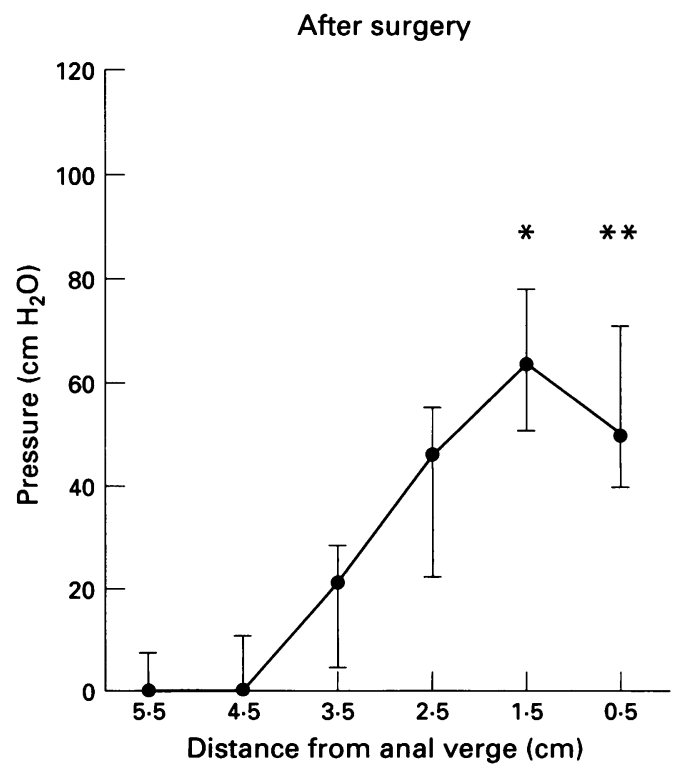

Figure 1: The resting anal sphincter pressure profile before and after restorative proctocolectomy $\left({ }^{\star} p=0.036,{ }^{\star} p=0.008\right)$. 
Before surgery - balloon deflated

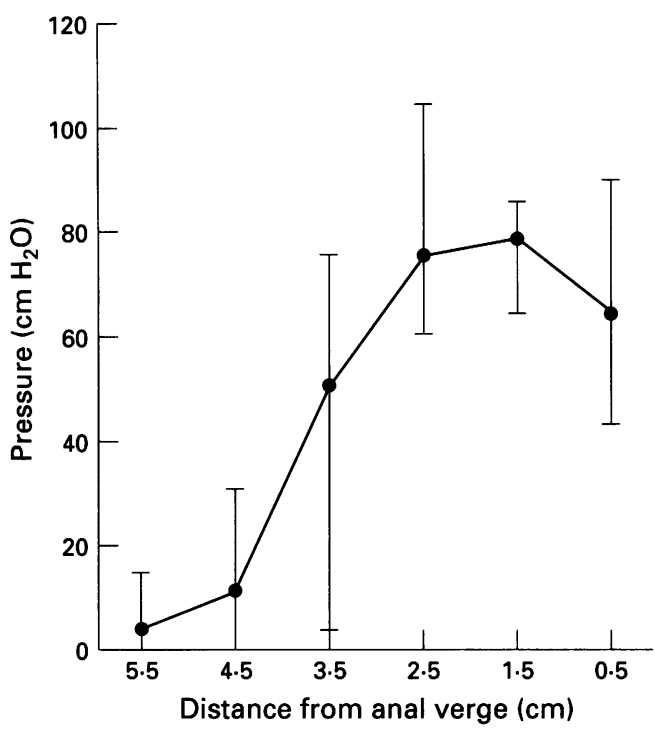

Before surgery - balloon inflated

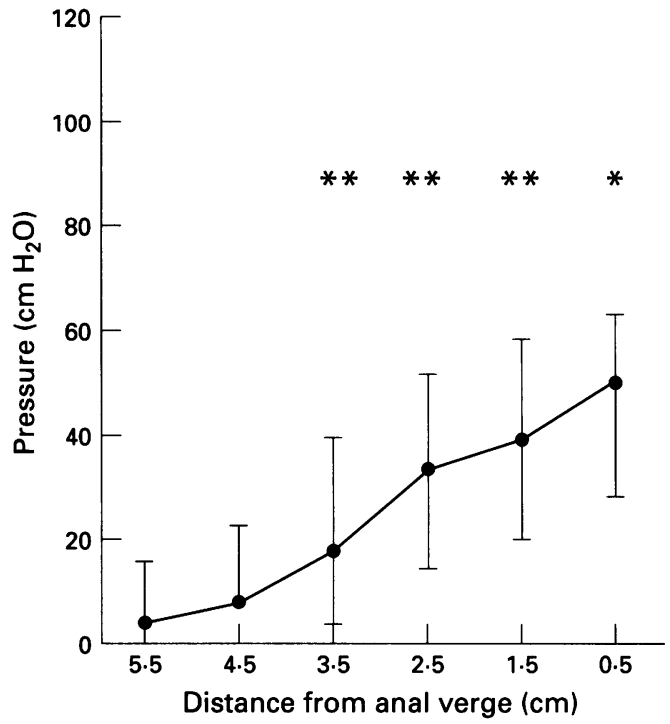

Figure 2: The response of the anal sphincter to distension of the rectum before restorative proctocolectomy $\left({ }^{\star} p=0.002\right.$, $\star \star p=0 \cdot 001)$.

seen during distension of the rectum before restorative proctocolectomy.

VOLUME OF DISTENSION REQUIRED TO PRODUCE INHIBITORY REFLEX

A significantly greater volume of distension was required after restorative proctocolectomy to produce the same degree of inhibition of the anal sphincter as that seen before operation: 100 (95-150) $\mathrm{ml}$ compared with 50 (40-100) $\mathrm{ml}$ of air $(\mathrm{p}=0.002)$.

\section{PRESSURE REQUIRED TO ELICIT INHIBITORY} REFLEX

In each patient the pressure within the intrarectal or intra-pouch balloon was measured at the time of maximum reflex inhibition of the anal sphincter. Before operation, the median pressure within the rectum that was required to produce maximum reflex inhibition of the anal

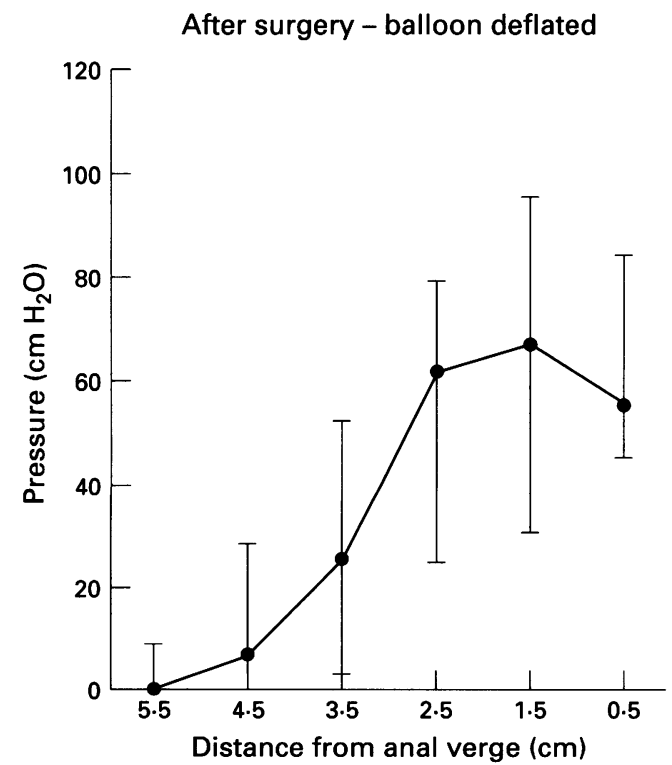

sphincter was $22 \cdot 3(14 \cdot 9-29 \cdot 1) \mathrm{cm} \mathrm{H}_{2} \mathrm{O}$ at 50 $(40-100) \mathrm{ml}$ of distension. After operation, distension of the pouch with $50 \mathrm{ml}$ of air produced a median pressure within the pouch of only $4.8(3.7-7.9) \quad \mathrm{cm} \mathrm{H}_{2} \mathrm{O} \quad(\mathrm{p}<0.001$ compared with pressure within the rectum before operation). After restorative proctocolectomy, maximum inhibition of the anal sphincter was observed in response to a median pressure of $16.0(11 \cdot 4-22 \cdot 4) \mathrm{cm} \mathrm{H}_{2} \mathrm{O}$ within the ileal pouch, a significantly greater pressure than that generated by distension of the pouch with $50 \mathrm{ml}$ of air $(p<0.001)$.

\section{CLINICAL RESULTS}

After restorative proctocolectomy, all 30 patients enjoyed perfect continence during the day, but two patients experienced minor leakage of mucus or faeces during sleep. Median bowel frequency was four times by day (range 2-9) and once at night (0-3). Each

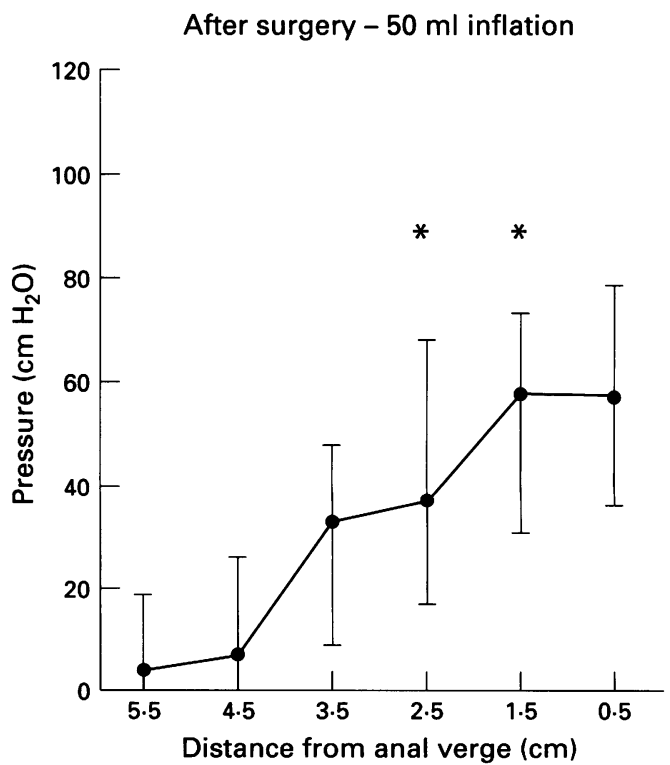

Figure 3: The response of the anal sphincter to distension of the ileal reservoir after restorative proctocolectomy with $50 \mathrm{ml}$ of air $\left({ }^{\star} p<0 \cdot 02\right)$ 
After surgery - balloon deflated

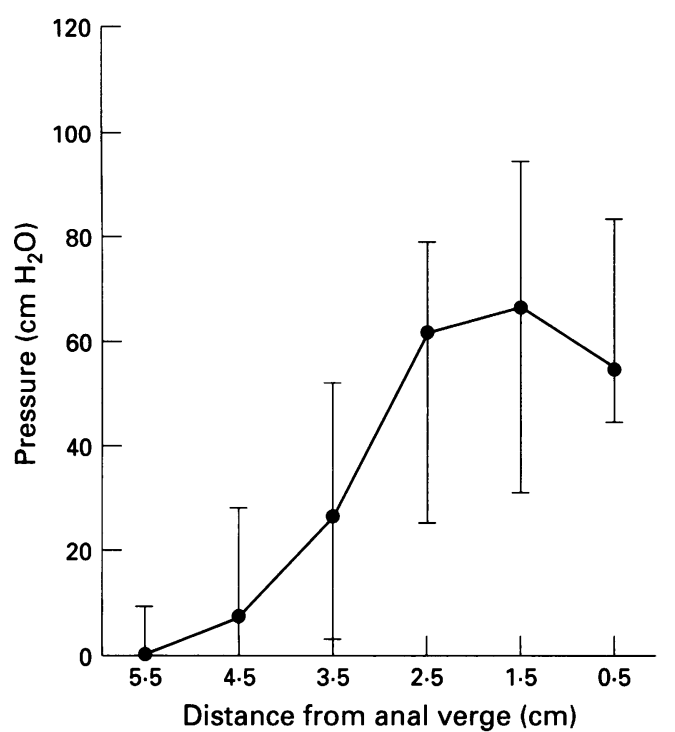

After surgery - balloon inflated

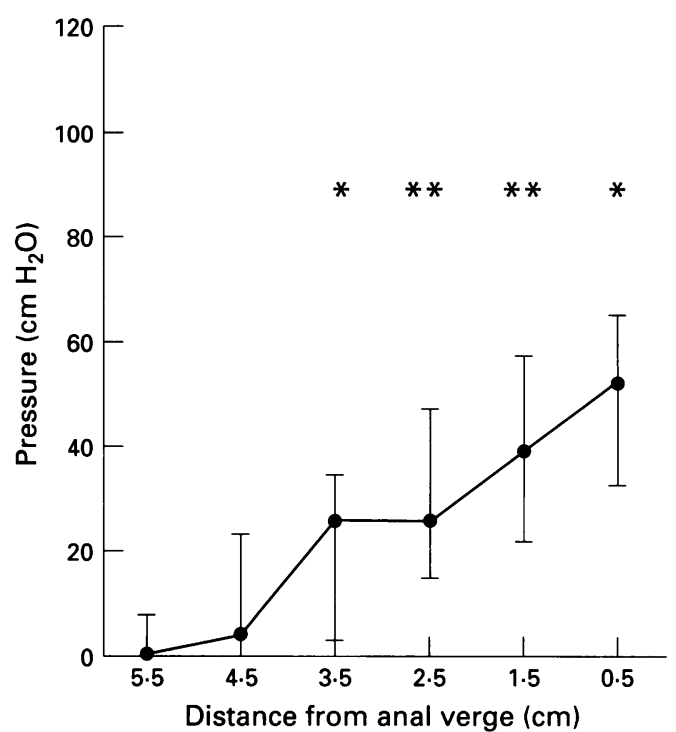

Figure 4: The maximal response of the anal sphincter to distension of the ileal reservoir $\left({ }^{\star} p=0.003,{ }^{\star \star} p<0.001\right)$.

patient could defer defecation for longer than 15 minutes and 29 patients could defer for longer than 30 minutes. Thirteen patients could discriminate with confidence between the presence of flatus and that of faeces in the pouch, and could pass flatus without having to visit a toilet. A further 12 patients could also discriminate between flatus and faeces but were not happy to release flatus without visiting the toilet. The remaining five patients could not distinguish between flatus and faeces but, nevertheless, enjoyed good anal continence.

\section{Discussion}

The recto-anal inhibitory reflex was first described by Gowers in $1877 .{ }^{8}$ In 1964 Bennett and Duthie investigated the reflex in detail and postulated a role for this phenomenon in anal sphincteric proprioception or sampling. ${ }^{1}$ Graduated reflex inhibition of the anal sphincter in response to distension of the rectum is thought to permit pressure in the rectum and upper anal canal to become equal: at the same time, inhibition of the more distal part of the sphincter near the anal margin is either absent or less pronounced. In this way, the sensitive epithelium of the upper anal canal might come in contact with, and sample rectal content. The proportion of patients in whom the recto-anal inhibitory reflex can still be elicited after restorative proctocolectomy has been variously reported to be $0 \%,{ }^{9} 12 \%, 10$ $64 \%,{ }^{11}$ and $95 \% .^{3}$ It has been claimed that the presence or absence of the reflex has little influence on the functional outcome, ${ }^{12}$ and that the reflex may therefore not be a prerequisite for the preservation of gross faecal continence. Nevertheless, continence after endo-anal ileoanal anastomosis has been described by the Mayo Clinic group to be less than perfect in 40 to $50 \%$ of patients, ${ }^{12}$ and although the recto-anal inhibitory reflex and sensation in the upper half of the anal canal may not be essential for gross continence, the loss of such normal physiological mechanisms may result in subtle impairment of anal function when compared with that of normal individuals. ${ }^{9}$

The precise method by which the ileal pouch-anal anastomosis is constructed seems from first principles to be central to whether or not the reflex function may return after restorative proctocolectomy. In the current debate about the advisability or otherwise of mucosectomy and endo-anal ileoanal anastomosis, complete excision of 'at risk' mucosa (of colitis and cancer) followed by endo-anal ileoanal anastomosis at the dentate line, is often recommended. ${ }^{1314}$ However, it seems likely that if the sensitive mucosa of the anal transitional zone is excised and the upper half of the internal sphincter splinted by the full thickness ileum that is pulled through, the ability of the upper anal canal to sample will be compromised, if not lost altogether. In contrast, the use of a stapling technique, to perform an end to end pouch-anal anastomosis, in which the entire anal canal is preserved, has the inherent physiological advantage that the entire anal transitional zone together with the whole internal anal sphincter are preserved, so that the sensitive part of the anal canal that is thought to be responsible for sampling is not disturbed. ${ }^{4} 15$

The 30 patients in this study were typical of patients who undergo this type of surgery for ulcerative colitis. Before operation, the reflex was present in each patient and was typical of that described by Bennett and Duthie, although the volume in the rectum that was required to produce maximum inhibition of the anal sphincter varied. For example, the volume of rectal distension needed to elicit reflex inhibition of the anal sphincter was less if the patient had undergone previous subtotal colectomy and ileostomy, defunctioning the anorectum, than in patients in whom the rectum had not been defunctioned.

A median of six months after restorative proctocolectomy or reversal of the ileostomy, inhibition of the anal sphincter by distension of the ileal reservoir was clearly demonstrated 
in all 30 patients. However, the amount of distension of the neorectum that was required to produce the same degree of inhibition of the sphincter was significantly greater after restorative proctocolectomy than that required before restorative proctocolectomy. Hence, it could be argued that the character of the anal sphincteric response to distension of the neorectum had changed. Certainly, the distensibility of rectum affected by a chronic inflammatory process such as ulcerative colitis must be significantly less than that of normal rectum. Before restorative proctocolectomy, however, when the pressure within the compliance balloon was calculated at a distending volume of $50 \mathrm{ml}$ of air, the median pressure was $22 \cdot 3$ (range 5.5-36.4) $\mathrm{cm}$ of water. Distension of the ileal reservoir with $50 \mathrm{ml}$ of air after restorative proctocolectomy produced a median pressure of only 4.8 (range $0-16$ ) $\mathrm{cm}$ of water within the pouch $(p<0.001$ compared with before operation). Distension of the pouch with a median of 100 (range $50-280$ ) $\mathrm{ml}$ of air produced pressures within the pouch approaching those observed before restorative proctocolectomy at $16 \cdot 0$ (range $3 \cdot 6-34 \cdot 3$ ) $\mathrm{cm}$ of water, significantly greater pressures $(p<0.001)$ than those generated by distension of the pouch with $50 \mathrm{ml}$ of air, but similar to the pressures required to produce inhibition of the sphincter before restorative proctocolectomy. It seems likely, therefore, that it is the transmission of pressure through the wall of the rectum or neorectum that is the important factor in eliciting inhibition of the anal sphincter. The anal transitional zone is known to have a rich sensory nervous supply. ${ }^{16}$ Although it is not possible, as yet, to say whether such reflex function is transmitted via neural pathways that have regenerated across the ileo-anal anastomosis, it is possible that pressure transmitted through the wall of the rectum or ileal reservoir could stimulate the upper anal canal resulting in reflex inhibition. Certainly, the Law of Laplace states that the pressure transmitted across the wall of a cylinder is proportional to the tension in the walls of that cylinder, which is in turn proportional to the amount of distension of the wall of the cylinder. ${ }^{17}$

In conclusion, we have shown previously that both motor ${ }^{4}$ and sensory ${ }^{18}$ functions of the anal sphincter were preserved better after a stapled, end to end anastomosis than after mucosectomy and endo-anal anastomosis. This study has shown that the third component of anal sphincteric function, namely automatic reflex function, is also preserved after restorative proctocolectomy with end to end anastomosis, and these findings thus lend further support to the idea that the entire anal sphincter should be preserved in the course of sphincter saving surgery. Admittedly, the high pressure zone within the sphincter encompasses not only the anal transitional zone but some rectal mucosa. Nevertheless, we believe that an end to end anastomosis of the pouch to the upper end of the anal high pressure zone should not be stigmatised as a 'pouch-low rectal anastomosis' with its implied risks of persistent colitis, dysplasia, and even carcinoma. ${ }^{16}$ We know of no evidence to date that the presence of columnar mucosa within the anal high pressure zone predisposes to the development either of dysplasia or of carcinoma. All forms of sphincter saving enteroanal surgery achieve gross anal continence, but we should now consider such modalities as the patients' ability to defer defecation and to discriminate between solid, liquid and gaseous rectal content. The anal sphincter is a marvellous structure, with subtle motor, sensory, and reflex mechanisms. Stripping of the anal mucosa down to the dentate line and endoanal ileo-anal anastomosis renders the sphincter weaker, ${ }^{4}$ sensation blunter, ${ }^{18}$ and abolishes the recto-anal inhibitory reflex altogether. ${ }^{11}$ The stapled ileo-anal, end to end anastomosis therefore holds the advantage in all three key areas of anal sphincter function.

This paper was presented to the Annual Meeting of the British Society of Gastroenterology, September, 1994. (Gut 1994; 35 (suppl 5): S31.)

1 Bennett RC, Duthie HL. The functional importance of the internal anal sphincter. Br f Surg 1964; 51: 355-7.

2 Lubowski DZ, Nicholls RJ, Swash M, Jordan MS. Neural control of internal anal sphincter function. Brf Surg 1987; 74: 668-70.

3 Sagar PM, Holdsworth PJ, Johnston D. Correlation between laboratory findings and clinical outcome after restorative proctocolectomy: serial studies in 20 patients with end-to-end pouch-anal anastomosis. Br f Surg 1991; with end-to- $67-70$.

4 Johnston D, Holdsworth PJ, Nasmyth DG, Neal DE, Primrose JN, Womack N, Axon ATR. Preservation of the entire anal canal in conservative proctocolectomy for ulcerative colitis: a pilot study comparing end-to-end ileoanal anastomosis without mucosal resection with mucosal proctectomy and endo-anal anastomosis. Br $\mathcal{F}$ Surg 1987 74: $940-4$.

5 Roe AM, Bartolo DCC, Mortensen NIM. A new method for assessment of anal sensation in various ano-rectal disorders. Br f Surg 1986; 73: 310-2.

6 Keighley MRB, Henry MM, Bartolo DCC, Mortensen NJM. Anorectal physiology measurement: report of a NJM. Anorectal physiology measurement:
working party. Br $\mathscr{f}$ Surg 1989; 75: 356-7.

7 Cohen L, Holliday M. Statistics for social scientists. London: Harper and Row, 1982.

8 Gowers WR. The automatic action of the sphincter ani. Proc $R$ Soc Lond 1877; 26: 77-84.

9 Pezim ME, Pemberton JH, Dozois RR. Enteric continence and the ileal pouch-anal procedure. Seminars in Surgical Oncology 1987; 3: 92-8.

10 Sun WM, Read NW, Katsinelos P, Donnelly TC, Shorthouse AJ. Anorectal function after restorative proctocolectomy and low anterior resection with coloanal proctocolectomy and low anterior resect

11 Nicholls RJ, Belliveau P, Neill M, Wilks $M$, Tabaqchali S. Restorative proctocolectomy with ileal reservoir: a pathophysiological assessment. Gut 1981; 22: 462-8.

12 Beart RW Jr, Dozois RR, Wolff BG, Pemberton JH. Mechanisms of continence. Lessons from the ileoana procedure. Am ₹ Surg 1985; 149: 31-4

13 Seouw-Choen, Tsunoda A, Nicholls RJ. Prospective randomised trial comparing anal function after handsewn ileo-anal anastomosis with mucosectomy versus stapled ileo-anal anastomosis in restorative proctocolectomy. $\mathrm{Br}$ Surg 1991; 78: 430-4.

14 Kelly KA. Anal sphincter-saving operations for chronic ulcerative colitis. Am f Surg 1992; 163: 5-11.

15 Martin LW, Torres AM, Fischer JE, Alexander F. The critical level for preservation of continence in the ileo-anal anastomosis. $\mathcal{F}$ Paediatr Surg 1985; 20: 664-7.

16 Duthie HL, Gairns FW. Sensory nerve-endings and sensa tion in the anal region of man. Br $\mathscr{f}$ Surg $1960 ; 47$ : tion in

17 West JB, ed. Best and Taylor's physiological basis of medical practice. 12th ed. Baltimore: Williams and Wilkins, 1990 18 Holdsworth PJ, Johnston D. Anal sensation after restorative proctocolectomy for ulcerative colitis. Br f Surg 1988; 75 993-6. 